\title{
1 Conserved abilities of individual recognition and genetically \\ 2 modulated social responses in young chicks (Gallus gallus)
}

4 Elisabetta Versace ${ }^{1,2,3^{*}}$, Morgana Ragusa ${ }^{3}$, Virginia Pallante ${ }^{3}$

$5 \quad{ }^{1}$ School of Biological and Chemical Sciences, Department of Biological and

6 Experimental Psychology, Queen Mary University of London, UK

$7 \quad{ }^{2}$ Alan Turing Institute, London, UK

$8{ }^{3}$ Center for Mind/Brain Sciences, University of Trento, Italy

9 *Corresponding author: e.versace@qmul.ac.uk, School of Biological and Chemical

10 Sciences, Department of Biological and Experimental Psychology, Queen Mary

11 University of London, Mile End Road 327, E1 4NS London (UK). Telephone: + 44 (0)

$12 \quad 2078828798$

\section{Abstract}

The ability to recognise familiar individuals and the motivation to stay in contact with conspecifics are important to establish social relationships from the beginning of life. To understand the genetic basis of early social behaviour, we studied the different responses to familiar/unfamiliar individuals and social reinstatement in 4-day-old domestic chicks

19 (Gallus gallus) in three genetically isolated breeds: Padovana, Polverara and Robusta. All breeds showed a similar ability to discriminate between familiar and unfamiliar 
21 individuals, staying closer to familiar individuals. Social reinstatement motivation

22 measured as the average distance between subjects, latency to the first step and

23 exploration of the arena (a proxy for the lack of fear), differed between breeds. More

24 socially motivated chicks that stayed in closer proximity, were also less fearful and

25 explored the environment more extensively. These results suggest that modulation of

26 social behaviour shows larger genetic variability than the ability to recognise social

27 partners, which appears to be an adaptive ability widespread at the species level even for

28 very young animals.

\section{Keywords}

31 Individual recognition, imprinting, social reinstatement, social motivation, chicks, Gallus

32 gallus, early cognition 


\section{Introduction}

In many species, the ability to recognise familiar individuals is important to establish social relationships from the first moments of life. In domestic chicks (Gallus gallus) and other precocial animals that move around soon after birth, the mechanism of imprinting enables to quickly learn the features of familiar individuals such as the mother and the siblings (Bateson, 1966; Bolhuis, 1991; McCabe, 2013; Vallortigara \& Versace, 2018).

After imprinting, hatchlings exhibit strong affiliative responses towards the imprinting stimulus while avoiding unfamiliar stimuli, a behaviour that requires the ability to recognise familiar individuals. Moreover, separation from the imprinting objects elicits attempts to signal and join the social partners (Jones \& Merry, 1988; B. R. Jones \& Williams, 1992; Suarez \& Gallup, 1983; Zajonc, Wilson, \& Rajecki, 1975), as well as adrenocortical activation in domestic chicks (Jones \& Williams, 1992). Imprinting is not limited to general species recognition, as initially hypothesised by Lorenz, but enables to discriminate between particular individuals. This is shown by the different affiliative and aggressive responses to familiar and stranger social partners of the same chicken breed (Rajecki, Ivins, \& Rein, 1976; Väisänen \& Jensen, 2004; Vallortigara, 1992; Vallortigara, Cozzutti, Tommasi, \& Rogers, 2001; Vallortigara \& Andrew, 1994; Zajonc et al., 1975 see also Schweitzer, Poindron, \& Arnould, 2009 for quails). Moreover, Johnson and Horn (1987) have shown that the ability of chicks to imprint on a specific hen depends on the intermediate and medial mesopallium (IMM) and Town (2011) has shown that this area responds differently to familiar and unfamiliar conspecifics. 
For wild hatchlings, the ability to imprint and recognise familiar individuals is important to identify the care giver and maintain flock/group cohesion. However, recognition of familiar individuals has been documented also in hatchlings of solitary species, such as land tortoises of different species (Versace, Damini, Caffini, \& Stancher, 2018). Filial imprinting is particularly suitable to investigate in the laboratory since imprinting can be established also for artificial objects that are more easily manipulated in appearance than living animals. Thanks to these features, imprinting has become a model system for memory, learning and social behaviour (Bateson, 1966; Bolhuis, 1991; Horn, 1985, 2004; McCabe, 2013, 2019). In the laboratory, imprinting is studied using well controlled artificial stimuli such as balls, cubes, cylinders or two-dimensional stimuli presented on cardboards or computer screens (Rosa-Salva et al., 2018; Versace, Schill, Nencini, \& Vallortigara, 2016; Versace, Spierings, Caffini, ten Cate, \& Vallortigara, 2017; Wood \& Wood, 2015). These experiments have shown that chicks discriminate subtle differences of the imprinting objects, such as rotation of the features located inside the imprinting object (Vallortigara \& Andrew, 1991), the configuration of items that compose the imprinting stimulus (Rosa-Salva et al., 2018) and even the underlying structure of the stimuli independent of their physical appearance (Martinho \& Kacelnik, 2016; Versace, Regolin, \& Vallortigara, 2006; Versace, Spierings, et al., 2017). Less is known on the genetic differences in the early ability of chicks to imprint on living objects and to discriminate between familiar and unfamiliar individuals. Väisänen and Jensen (2004) have explored the differences in responses to familiar and unfamiliar social stimuli in red jungle fowls (a breed considered to be close to the ancestral undomesticated chicken (Miao et al., 2013) and White Leghorns (a modern breed 
79 selected for laying eggs), using 3-4 week old animals. This study showed greater

80 affiliative responses in White Leghorn compared to red jungle fowls but did not clarify

81 the onset of these differences.

82

83

Here we explore the genetic differences of chicks in responding to familiar/unfamiliar individuals in 4-day old chicks of three different breeds of domestic fowl: the Padovana, Polverara and Robusta breed. Chicks originated in the same farm within the conservation programme Co.Va, that kept these local breeds in genetic isolation for more than 20 years (De Marchi, Cassandro, Targhetta, Baruchello, \& Notter, 2005). This particular arrangement reduced the environmental differences while ensuring low admixture between breeds (Zanetti, De Marchi, Dalvit, \& Cassandro, 2010). We previously investigated the predisposed visual preferences of these breeds to approach a stuffed hen vs. a scrambled version of it in visually naïve chicks (Versace, Fracasso, Baldan, Dalle Zotte, \& Vallortigara, 2017). Predisposed responses precede imprinting for they are exhibited before any prior visual experience has occurred and do not depend on experience (Di Giorgio et al., 2017). When given the choice between a stuffed hen and a scrambled version of it, we observed that all three breeds initially preferred to orient towards the stuffed hen, which is the predisposed stimulus that several breeds preferentially approach (see Egorova \& Anokhin, 2003; Johnson \& Horn, 1988; Mayer, Rosa-Salva, Lorenzi, \& Vallortigara, 2016; Versace, Fracasso, Baldan, Dalle Zotte, \& Vallortigara, 2017). Interestingly, we observed a difference between breeds as early as the first 10 minutes of visual experience: while the Polverara breed showed a steady attachment for the stuffed hen throughout the test, the Robusta and Padovana 
101 breeds were attracted by the alternative stimulus. This suggests that behavioural

102 strategies that drive early attachment and orientation have a genetic basis, and that

103 genetic differences are apparent in the first minutes of visual experience. It is not clear,

104 though, whether differences in the ability to recognise familiar individuals and social

105 motivation are present between these breeds. The peculiar skull and brain anatomy of

106 the Padovana breed is a further reason of interest for these breeds. Both the Padovana

107 and Polverara breed have a striking crest on the head but only in the Padovana breed the

108 crest covers a perforated skull with an associated enlargement of the brain (Verdiglione

$109 \&$ Rizzi, 2018). The behavioural and cognitive implications of this striking anatomy

110 remain elusive, although Darwin (1868) hypothesised potential deficits in a closely

111 related breed, the white crested Polish. Historical documents suggest that the Padovana

112 breed, whose traces go back to Roman times (Brothwelp, 1979), was introduced in Italy

113 from Poland more than seven centuries ago (De Marchi et al., 2005), originating from

114 the white crested Polish. In the White crested Polish/Padovana breed the endocranium

115 is enlarged and the brain has dramatically expanded to fill this gap (Frahm \&

116 Rehkamper, 1998). It is not clear which behavioural consequences this peculiar brain

117 organisation has produced, and whether the abilities of individual recognition and

118 affiliative responses for this breed differ from those of other chickens.

To investigate the genetic variability in early individual recognition and in social

motivation we tested the three breeds in an open field test. In this setting, chicks are

121 located in a novel empty arena larger than their home cage and their spontaneous

122 behaviour is observed in the presence of familiar or stranger conspecifics. The ability of 
123 chicks to recognise familiar/stranger individuals can be inferred looking at whether the

124 distance kept between familiar animals is different. Due to the process of filial

125 imprinting, familiar chicks are expected to stay closer than stranger chicks, as previously

126 documented (see for instance Vallortigara, 1992; Zajonc et al., 1975). Based on their

127 antipredatory and affiliative behaviour, it has been suggested that animals located in an

128 open field with other conspecifics experience both the fear of being in an open

129 environment - which has the effect of reducing activity and exploration -, and social

130 reinstatement, namely the motivation to reach the group and remain in contact with

131 conspecifics (Suarez \& Gallup, 1983; Vallortigara, 1992; Vallortigara, Cailotto, \&

132 Zanforlin, 1990). In a range of species, greater latency of movement/tonic immobility

133 indicates antipredatory responses, while shorter distance between individuals indicates

134 stronger social/reinstatement motivation (Jones, Mills, \& Faure, 1996; Versace, Caffini,

135 Werkhoven, \& Bivort, 2019).

\section{Methods}

\subsection{Breeds and conservation scheme}

139 We studied three genetically isolated breeds of domestic fowl (Gallus gallus) raised in the

140 same farm (Istituto Istruzione Superiore Agraria "Duca degli Abruzzi”, Padova, Italy):

141 Padovana, Polverara and Robusta maculata. These breeds entered the Co.Va

142 conservation project more than 20 years before this project (De Marchi et al., 2005). The

143 breeding and conservation scheme included no gene flow between breeds and were

144 aimed at increasing the number of pure breed animals while maintaining genetic 
145 variability within the breed. We included individuals from gold, silver and buff Padovana

146 and white and black Polverara, because previous studies showed high homogeneity

147 within these breeds (Zanetti, De Marchi, Abbadi, \& Cassandro, 2011; Zanetti et al.,

148 2010). The Robusta maculata breed was developed in 1965 from crosses between Tawny

149 Orpingtons and White Americans. Zanetti et al. (2010) documented genetic isolation

150 (low level of admixture) between these breeds and a closer phylogenetic relationship

151 between Padovana and Polverara, which are also more similar at phenotypic level

152 compared to Robusta. More details are provided in Versace et al. (2017).

\subsection{Subjects and rearing conditions}

155

156

157

158

159

160

161

162

163

164

165
We tested 221 pairs of chicks: 94 pairs of the Padovana breed (PD), 88 pairs of the Polverara breed (PL), 39 pairs of the Robusta breed (RB). During the test, 156 pairs moved: 58 Padovana, 60 Polverara and 38 Robusta. Eggs were obtained from the Agricultural High School "Duca degli Abruzzi" (Padova, Italy), which is pursuing the Co.Va conservation programme for the maintenance of local biodiversity described above (De Marchi et al., 2005). We incubated and hatched eggs in darkness at $37.7^{\circ} \mathrm{C}$. During incubation, humidity was kept at $40 \%$ and then increased to $60 \%$ during the last three days of incubation. Chicks hatched in groups of the same breed and were then housed in pairs of the same breed within 24 hours from hatching without any visual exposure to conspecifics prior to housing. Chicks were maintained in standard rearing conditions (temperature $28^{\circ} \mathrm{C}, 14: 10$ day:night cycle) for three days in $28 \times 38 \times 32 \mathrm{~cm}$ 
166

167 donated to local farmers.

cages, and tested at an age of 4 days after hatching. After the experiments, animals were

\subsection{Apparatus}

The test apparatus used for the test was a black square area $(40 \times 40 \times 36 \mathrm{~cm})$, illuminated with an incandescent lamp (100 W) located $1 \mathrm{~m}$ above the centre of the arena. A camera

172 recorded the experimental scene from above during the test.

\subsection{Test procedure}

175 The experiment consisted of two phases: a familiarization phase and a test phase (see

176 Figure 1). The familiarization phase started soon after hatching (day post hatching 0 ) and

177 lasted 3 days. During this phase a pair of chicks of the same breed was housed in the

178 same cage. At test, each subject was visually isolated for 10-15 minutes in an opaque box

179 (14.5 cm height, $8.5 \mathrm{~cm}$ large, $11 \mathrm{~cm}$ width) located inside its cage and then transferred 180 to the testing room together with another experimental subject. During the test we 181 observed two chicks previously housed together (Familiar condition) or previously housed with a different animal (Stranger condition). At the beginning of the test, 183 experimental chicks were placed simultaneously in two opposite corners of the arena and left free to move for 5 minutes. 


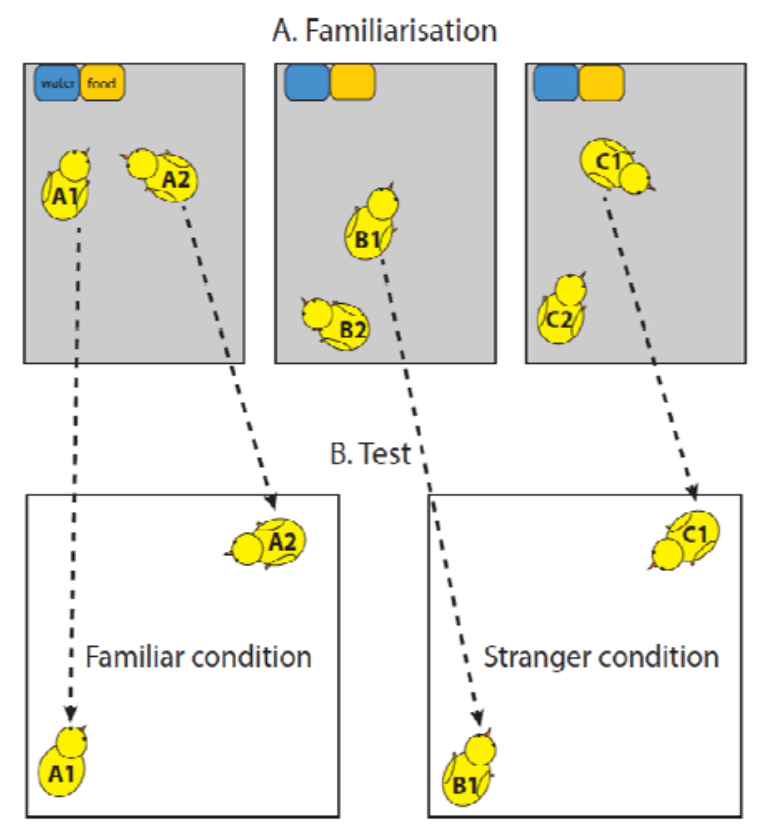

186 Figure 1. (A) Chicks were initially housed with another chick of the same breed for three days

187 (familiarisation). (B) At test, chicks were located in a new arena either with the familiar companion

188 (Familiar condition) or with a novel chick (Stranger condition). For each pair we recorded the latency

189 of the first step, the distance between the centroid of the chicks and overall distance run.

\subsection{Data analysis}

192 We initially established whether chicks in the pair moved or remained still throughout

193 the test and counted how many pairs moved/did not move during the test. We used a

194 Chi-square test to check whether more pairs moved in the Stranger or in the Familiar 195 condition.

For all pairs that moved, we used an Anova to analyse the average distance $(\mathrm{cm})$

197 between the centroid of subjects throughout the test, the overall distance moved by the pair $(\mathrm{cm})$ and the average latency of the first step (s) using Condition (familiar, stranger), 
199 Breed (Padovana, Polverara, Robusta) and their interaction as independent variables.

200 Exploratory analyses showed that a log-transformation of the distance moved and

201 latency normalised the residuals of these variables, hence we used log-transformed

202 values for these analyses. We ran post-hoc t-tests to explore significant differences. We

203 also analysed the relation between latency, distance run and distance between subjects

204 using the Spearman rank order correlation test and fitting linear and polynomial models

205 until finding the minimal adequate model. Significance level was set to $\mathrm{p}<0.05$. Statistical

206 analyses were performed with the R software (version 3.5.2).

\section{Results}

\subsection{Pairs that moved in the Familiar and Stranger condition}

There was no significant difference in the frequency of pairs that moved/did not move

between the Familiar and Stranger condition (X-squared $=0.834, \mathrm{df}=1, \mathrm{p}=0.361$ ) or

Breed (X-squared $=0.989, \mathrm{df}=2, \mathrm{p}=0.610)$.

\subsection{Distance between individuals}

215 Looking at the log-transformed distance between subjects we found a significant effect

216 of Condition $\left(\mathrm{F}_{1,150}=8.311, \mathrm{p}=0.005\right)$ and Breed $\left(\mathrm{F}_{2,150}=5.664, \mathrm{p}=0.004\right)$ and no

217 significant interaction $\left(\mathrm{F}_{2,150}=0.155, \mathrm{p}=0.857\right)$. These results are shown in Figure 2.

218 Familiar chicks stayed closer than stranger chicks $(t=-2.817, \mathrm{df}=153.34, \mathrm{p}=0.005)$. The 
219 average distance between Familiar chicks was $17.57 \mathrm{~cm}$ (median $10.26 \mathrm{~cm}$ ), the average 220 distance between Stranger chicks $20.75 \mathrm{~cm}$ (median $15.35 \mathrm{~cm})$.

A

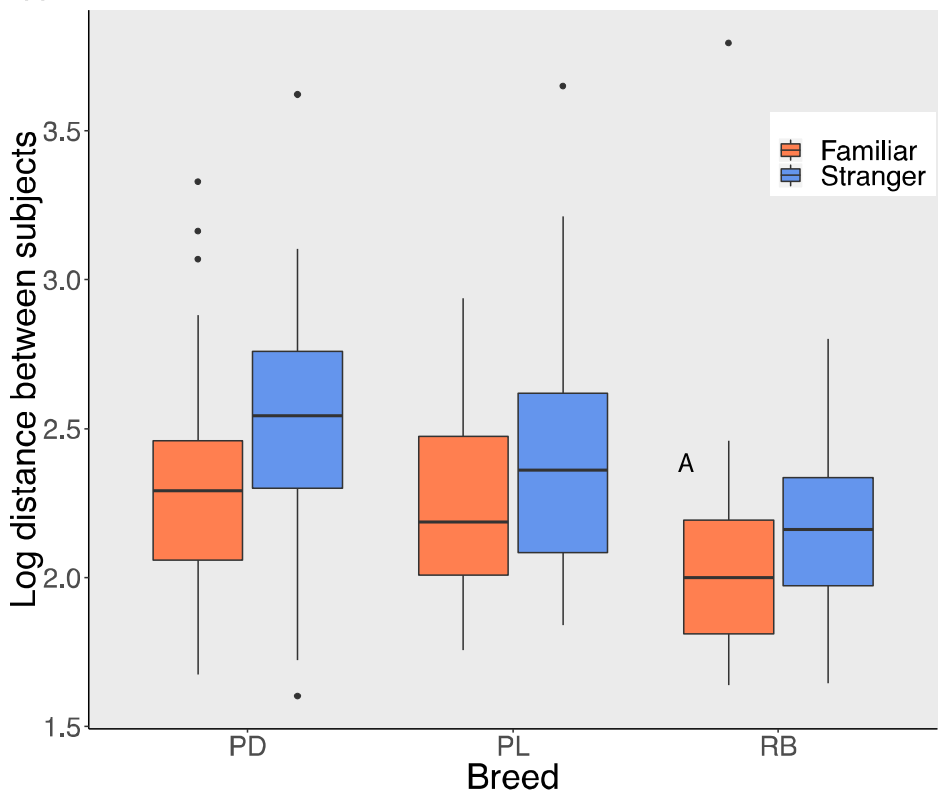

B

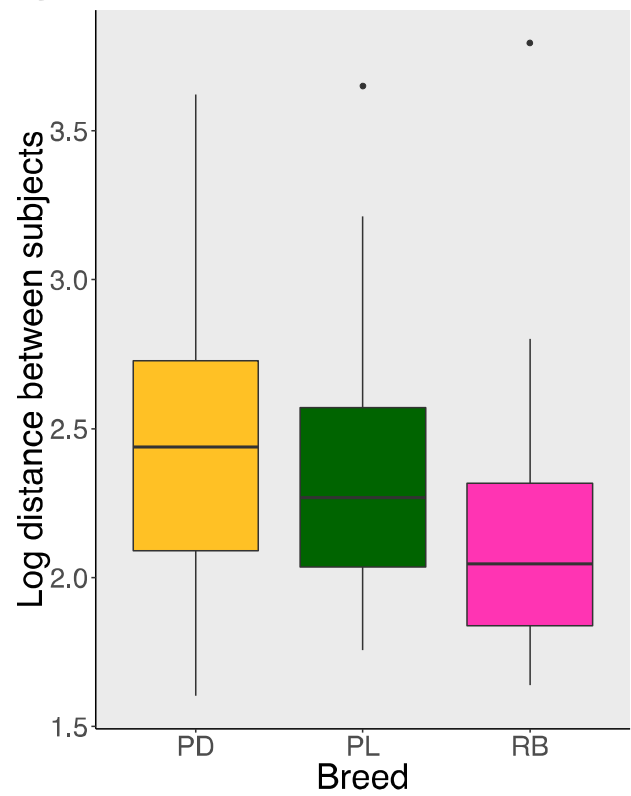

224

225

226

227

228

229

230

231

232

Figure 2. The boxplots show (A) for each condition (Familiar, Stranger) and (B) breed (PD=Padovana, $\mathrm{PL}=$ Polverara, $\mathrm{RB}=$ Robusta) the median, quartiles, maximum, minimum and outliers of the distance between subjects expressed in log centimetres.

\subsection{Distance run}

Analysing the overall distance run in each pair, we found a significant effect of Breed $\left(\mathrm{F}_{2,150}=6.102, \mathrm{p}=0.003\right)$ and no significant effect of Condition $\left(\mathrm{F}_{1,150}=0.409, \mathrm{p}=0.523\right)$ and no significant interaction $\left(\mathrm{F}_{2,150}=1.027, \mathrm{p}=0.360\right)$. These results are shown in Figure 3. 
234

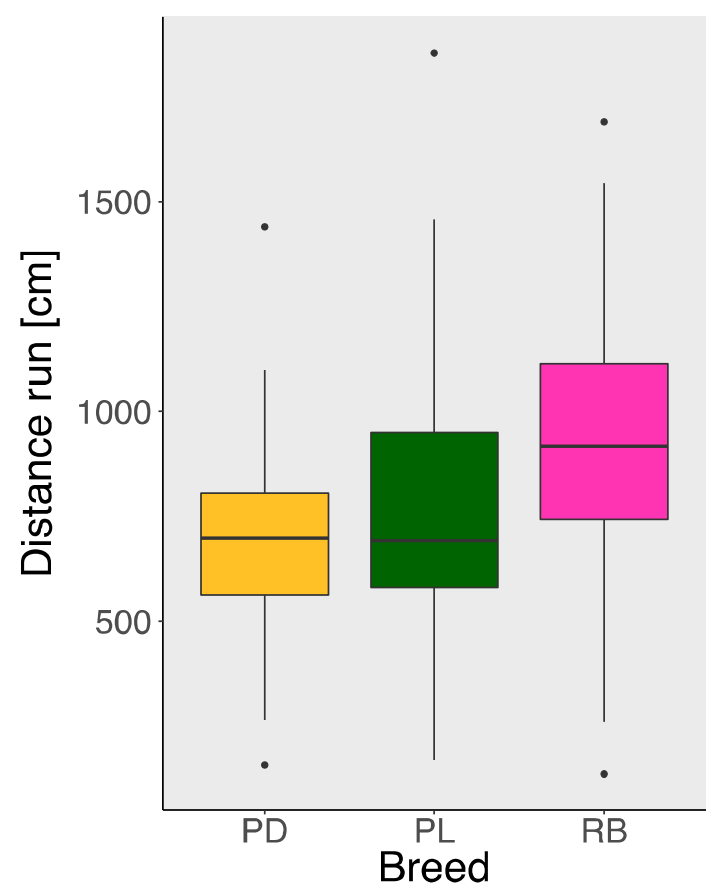

Figure 3. The boxplots show for each breed ( $\mathrm{PD}=$ Padovana, $\mathrm{PL}=$ Polverara, $\mathrm{RB}=$ Robusta) the median, quartiles, maximum, minimum and outliers of the distance run expressed in centimetres.

Polverara chicks did not run significantly more than Padovana chicks $(\mathrm{t}=1.890$, $\mathrm{df}=110.13, \mathrm{p}=0.061)$ although there was a trend in this direction, Robusta chicks ran significantly more than Polverara chicks $(\mathrm{t}=2.530, \mathrm{df}=71.406, \mathrm{p}=0.014)$, and significantly more than Padovana chicks $(\mathrm{t}=4.186, \mathrm{df}=58.757, \mathrm{p}<0.001)$.

\subsection{Latency first step}

Analysing the latency of the first step in each pair, we observed a significant effect of Condition $\left(\mathrm{F}_{2,150}=4.026, \mathrm{p}=0.047\right.$, with chicks in the Familiar condition moving sooner than chicks in the Stranger condition) and Breed $\left(\mathrm{F}_{2,150}=11.02, \mathrm{p}<0.001\right)$ and no 
247 significant interaction $\left(\mathrm{F}_{2,150}=0.336, \mathrm{p}=0.715\right)$. The mean latency for the Familiar

36 s). The results are shown in Figure 4.

250

A

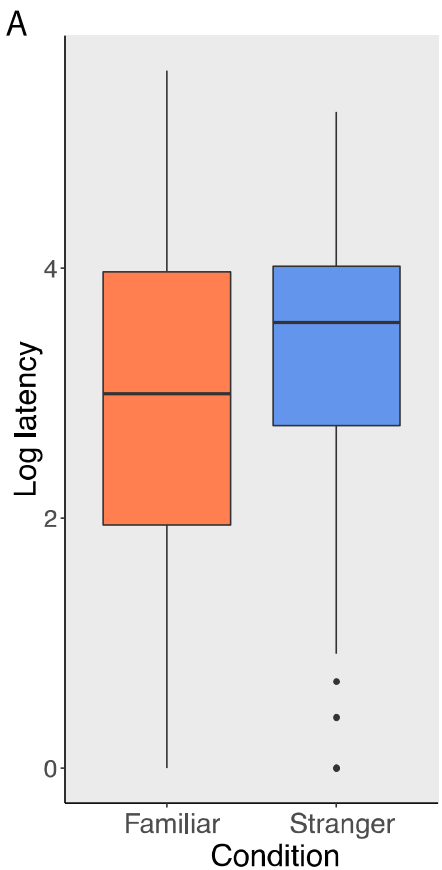

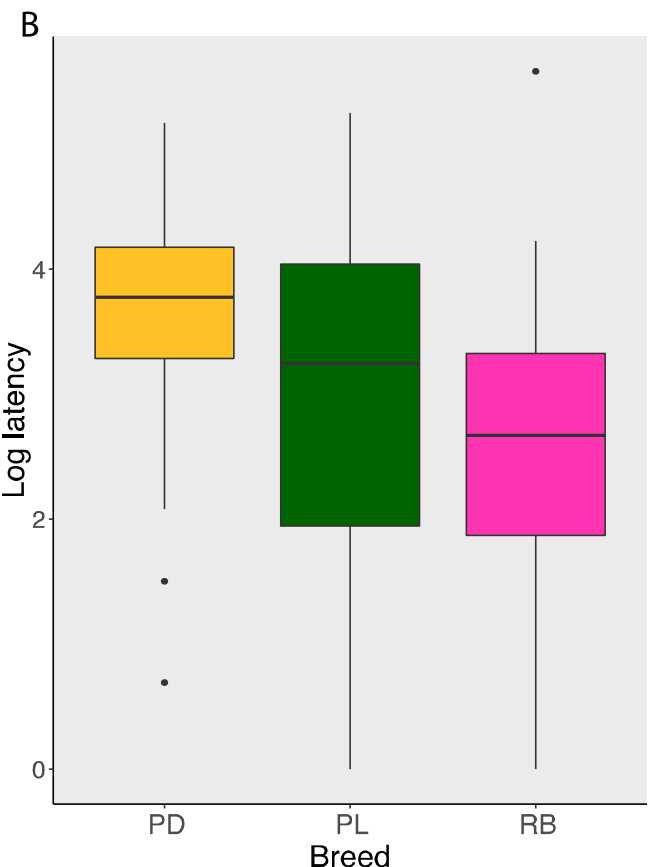

251

252

253

254

255

256

257

258

259

Figure 4. The boxplots show for each (A) condition (Familiar, Stranger) and (B) breed (PD=Padovana, $\mathrm{PL}=$ Polverara, $\mathrm{RB}=$ Robusta) the median, quartiles, maximum, minimum and outliers of the pair latency of the first step expressed in log seconds.

Polverara chicks moved significantly earlier than Padovana chicks $(t=-27.937, d f=78.274$, $\mathrm{p}<0.001)$, Robusta chicks moved significantly earlier than Polverara chicks $(\mathrm{t}=-27.229$, $\mathrm{df}=71.209, \mathrm{p}<0.001$ ), and also Robusta chicks moved significantly earlier than Padovana chicks $(\mathrm{t}=-25.87, \mathrm{df}=42.701, \mathrm{p}<0.001)$. 


\subsection{Relation between latency, distance between subjects and distance run}

We observed a significant positive correlation between the latency of the first step and the average distance between subjects $(S=162850, \mathrm{p}<0.001$, rho $=0.743$, see Figure $5 \mathrm{~A})$ and a significant negative correlation between the latency of the first step and the distance run $(S=899280, \mathrm{p}<0.001$, rho $=-0.421$, see Figure $5 B)$.
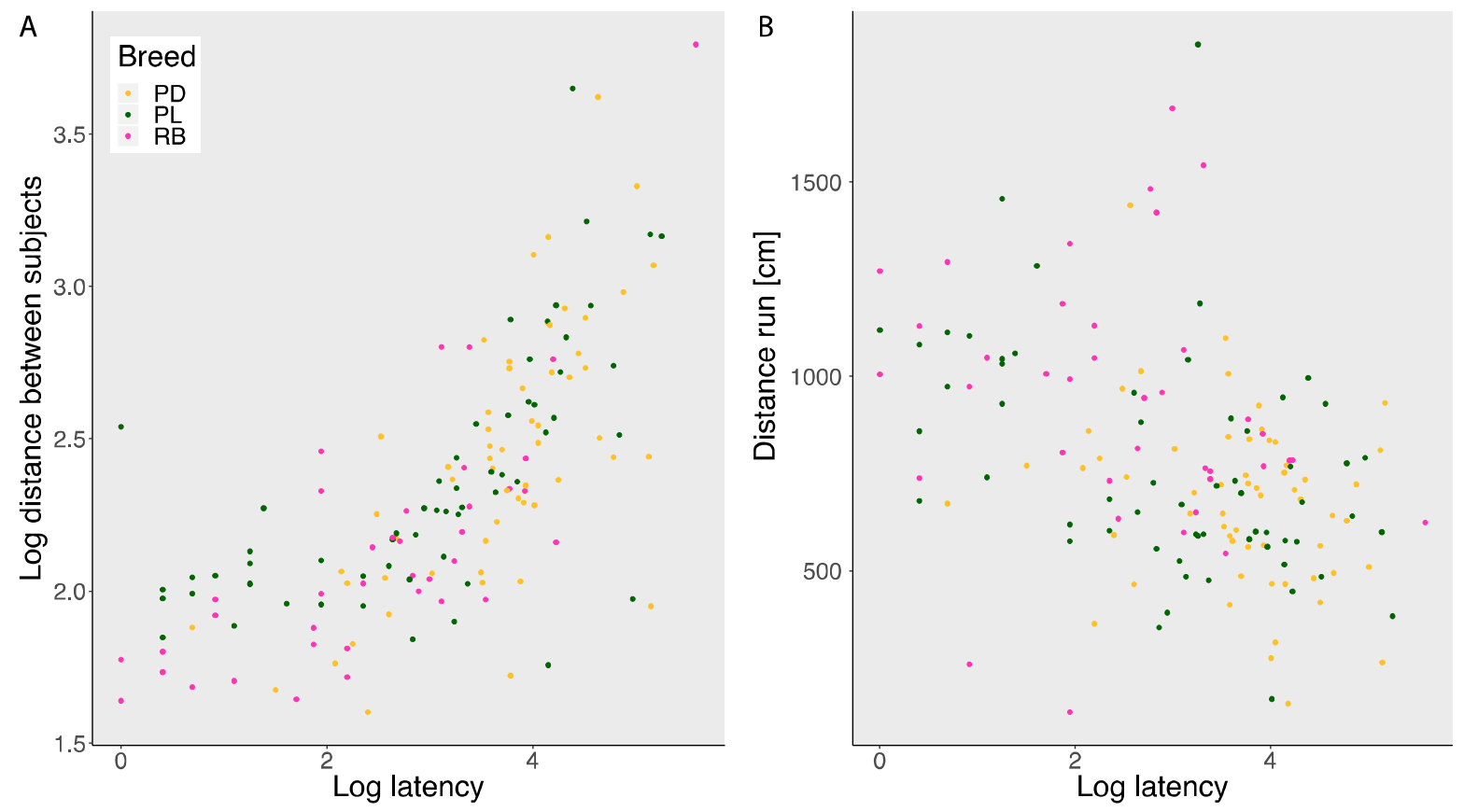

Figure 5. The scatterplots show the relation between (A) latency of the first step and average distance between subjects and (B) latency of the first step and distance run.

The minimal adequate model for the dependent variable Distance between subjects using as predictors Latency, Condition and Breed included a quadratic polynomial with Latency $\left(\mathrm{F}_{2,150}=98.035, \mathrm{p}<0.01\right)$, Condition $\left(\mathrm{F}_{1,150}=7.13, \mathrm{p}=0.008\right)$ and Latency $\mathrm{x}$ Condition $\left(\mathrm{F}_{2,150}=4.77, \mathrm{p}=0.001\right)$ as significant effects. The full table of coefficients is reported in Table 1. 


\begin{tabular}{|l|l|l|l|l|}
\hline & Estimate & Std. Error & T value & $\operatorname{Pr}(>|\mathrm{t}|)$ \\
\hline Intercept & & & & \\
\hline Latency (linear) & 2.266 & 0.032 & 70.122 & $<2 \mathrm{e}-16$ \\
\hline Latency (quadratic) & 3.138 & 0.370 & 8.493 & $1.83 \mathrm{e}-14$ \\
\hline Condition (Stranger) & 0.886 & 0.366 & 2.421 & 0.017 \\
\hline Latency (linear) x Condition & 0.120 & 0.045 & 2.642 & 0.009 \\
\hline Latency (quadratic) x Condition & 1.135 & 0.576 & 1.970 & 0.051 \\
\hline Residual standard error: 0.2797 on 150 degrees of freedom & 0.018 \\
\hline Multiple R-squared: 0.587 & 0.572 & 2.400 & \\
\hline F-statistic: 42.55 on 5 and $150 \mathrm{df}, \mathrm{p}<2.2 \mathrm{e}-16$ \\
\hline
\end{tabular}

Distance between subjects using as predictors Latency, Condition and Breed.

\begin{tabular}{|l|l|l|l|l|}
\hline & Estimate & $\begin{array}{l}\text { Std. } \\
\text { Error }\end{array}$ & T value & $\operatorname{Pr}(>|\mathrm{t}|)$ \\
\hline Intercept & 715.233 & 42.460 & 16.845 & $<2 \mathrm{e}-16$ \\
\hline Latency (linear) & -1156.56 & 286.562 & -4.036 & $<0.001$ \\
\hline Condition (Stranger) & -3.876 & 42.880 & 0.090 & 0.928 \\
\hline Breed (PL) & 40.333 & 50.206 & 0.803 & 0.423 \\
\hline Breed (RB) & 168.909 & 59.122 & 2.857 & 0.005 \\
\hline
\end{tabular}

Table 2. This table shows the coefficients of the minimal adequate model for the dependent variable 


\section{Discussion}

287 From the beginning of life, the ability to recognise familiar individuals and the 288 motivation to stay in contact with conspecifics are important to establish social 289 relationships. Little is known, though, on whether early social behaviours have a genetic 290 basis that determines behavioural differences. To address this issue, we focused on

291 domestic chicks (Gallus gallus). Chicks are an ideal model to investigate the first social

292 responses not only because they are a precocial species (Versace \& Vallortigara, 2015;

293 Versace, 2017) and move around autonomously soon after birth but also because they

294 live in flocks and have to recognise the mother and siblings to maintain social cohesion

295 (Nicol, 2015). We previously showed that the initial predisposition to orient towards a

296 (stuffed) hen does not vary between breeds, while exploratory responses to social stimuli

297 differ between breeds after just 10 minutes of experience (Versace, Fracasso, Baldan,

298 Dalle Zotte, \& Vallortigara, 2017). Here, we investigated early social responses mediated

299 by previous social experience and learning. We tested whether 4 -day-old chicks have

300 standing genetic variation for the ability to recognise conspecifics and social

301 reinstatement by using three genetically isolated breeds: Padovana, Polverara and

302 Robusta.

304 individuals and recognise a familiar one. As a proxy for recognition, we used the

305 different distance kept between familiar and unfamiliar individuals. When located in a

306 new environment with a familiar or an unfamiliar chick, all tested breeds equally

307 discriminated between familiar and unfamiliar individuals staying significantly closer to 
308 familiar chicks. and showing shorter latency of movement with pairs of familiar

309 individuals. Even the Padovana breed, that shows the neuroanatomical peculiarity of a

310 perforated skull with an associated enlargement of the brain (Verdiglione \& Rizzi, 2018),

311 did not show cognitive differences in this ability. This performance of Padovana chicks

312 suggests that the behavioural limitations noticed by Darwin (1868) in the white crested

313 Polish - a breed ancestral to Padovana (De Marchi, Dalvit, Targhetta, \& Cassandro,

314 2005; Verdiglione \& Rizzi, 2018) - do not derive from deficits in social motivation or

315 individual recognition (they might instead be due to difficulties in visual perception

316 linked to the long plumage of the crest as suggested by Vallortigara, personal

317 communication). Hence, the ability to promptly recognise familiar individuals appeared

318 widespread at the species level in chickens. Previous studies conducted on quails

319 (Coturnix coturnix japonica) (Kovach, 1990) showed a slow response to selection for

320 low/high imprintability. In this study, imprintability was selected as low/high ability to

321 exhibit imprinting responses for colours that were not initially preferred by young birds.

322 The observed sluggish response to selection for imprintability observed in quails is in

323 line with the absence of interbreed differences in the recognition of familiar individuals

324 that we have documented in chicks.

We have previously shown that even hatchlings of non-social species such as

tortoises are able to recognise familiar and unfamiliar individuals in the first days of life

327 (Versace, Damini, Caffini, \& Stancher, 2018). The early age and little experience required

328 (see also Suarez \& Gallup, 1983; Vallortigara, 1992; Zajonc et al., 1975), together with

329 the low genetic variability of this trait, shows how crucial individual recognition is at the 
onset of life for a range of different species. This contrasts with other social traits that showed significant genetic variability. In fact, we observed very clear differences between breeds and conditions when looking at measures of social reinstatement and fear in an open field. We measured social reinstatement, the motivation to join the social group and keep in contact with it, looking at the average distance between subjects. Shorter distance indicates greater social reinstatement motivation (Jones et al., 1996; Schweitzer et al., 2009; Suarez \& Gallup, 1983; Vallortigara et al., 1990; Vallortigara, 1992). Both the Polverara and Padovana breed, that are closely genetically related (Zanetti et al., 2010), maintained a larger distance than the Robusta breed, providing another indication of the fact that the observed differences have a genetic basis. We also assessed the fear elicited by being in a novel open field by looking at the latency to the first step and overall distance run. Since an adaptive antipredator response for chicks in an open field is freezing/tonic immobility, fear is expected to induce greater latency, and less exploration in the arena as antipredator behaviours. We observed that chicks with lower latency stayed closer and explored the arena more extensively. While fear/antipredatory responses and social reinstatement can dissociate (for instance with short distance between subjects that indicates high social reinstatement and little distance moved that indicates high fear), we observed that they were inversely correlated. This shows that pairs of chicks that approached each other explored the arena while remaining in close proximity.

Differences in social reinstatement and fear responses were apparent from the first days of life, in animals with very limited social experience. The differences in social 
reinstatement and fear had a clear genetic basis, with an effect of breed on latency, distance run and distance between individuals. In particular, the Robusta breed showed the shortest latency and distance between subjects as well as greater distance run during the test. These results are in line with the fact that quails respond to selection for high/low social reinstatement and fear (Formanek et al., 2008; Mills \& Faure, 1991; Mills, Jones, \& Michel, 1995), that older chicks of jungle fowl and White Leghorn exhibit different social reinstatement behaviour (Väisänen \& Jensen, 2004), and that neonate chicks differ in exploratory responses to social stimuli (Versace, Fracasso, Baldan, Dalle Zotte, \& Vallortigara, 2017).

Our findings suggest that the modulation of social behaviour shows larger genetic variability than the ability of recognizing familiar individuals. This points at the crucial adaptive role of individual recognition, an ability widespread across taxa and available from the earliest developmental stages also in tortoises (Versace, Damini, Caffini, \& Stancher, 2018). Interestingly, while we have shown that chicks consistently tend to aggregate with other individuals, tortoise hatchlings - that are solitary until reaching sexual maturity - ignore familiar individuals and avoid strangers (Versace, Damini, Caffini, \& Stancher, 2018). The ability to promptly recognize familiar individuals can hence sustain both affiliative and avoidance responses. The pivotal role of individual recognition is apparent in invertebrates as well. For instance, in studying aggression, Yurkovic et al. (2006) have documented the ability of fruit flies to respond differently to familiar and unfamiliar opponents. Not only familiar opponents had significantly fewer encounters but the fighting strategies depended on whether the opponent was familiar 
374 or unfamiliar: losers tested with unfamiliar winners were more aggressive than losers

375 paired with familiar winners. Individual recognition has been documented in other

376 insects such as paper wasps (Tibbetts, 2002; Tibbetts \& Dale, 2007) and ants (D’Ettorre

377 \& Heinze, 2005). It hence appears that individual recognition has a crucial role in a

378 broad comparative context. Using newly hatched chicks of different breeds, we have

379 shown the ability to recognize familiar individuals and differentially respond to them is

380 widespread in this species from the earliest stages of life. We suggest that identifying the

381 core abilities exhibited by young animals at the beginning of life might also guide experts

382 in artificial intelligence in understanding which are the fundamental components of

383 general intelligence (Versace, Martinho-Truswell, Kacelnik, \& Vallortigara, 2018).

384 Further studies should clarify the role of different perceptive cues chicks in

385 discriminating between familiar individuals.

\section{Animal welfare note}

All experiments comply with the ASAB/ABS Guidelines for the Use of Animals in

Research and with the current Italian and European Community laws for the ethical

treatment of animals and the experimental procedures were approved by the Ethical

Committee of University of Trento and licensed by the Italian Health Ministry (permit 
395

396

397

398

399

400

401

402

403

404

405

406

407

408

409

410

411

412

413

414

\section{Acknowledgements}

This work was funded by the Royal Society Research Grant RGS $\backslash R 1 \backslash 191185$.

\section{References}

Bateson, P. (1966). The characteristics and context of imprinting. Biological Reviews of the Cambridge Philosophical Society, 41(2), 177-211.

Bolhuis, J. J. (1991). Mechanisms of avian imprinting: a review. Biological Reviews, 66(4), 303-345. https://doi.org/10.1111/j.1469-185X.1991.tb01145.x

Brothwelp, D. (1979). Roman Evidence of a Crested Form of Domestic Fowl, as Indicated by a Skull Showing Associated Cerebral Hernia. Journal of Archaeological Scienc, 6, 291-293.

D’Ettorre, P., \& Heinze, J. (2005). Individual recognition in ant queens. Current Biology, 15(23), 2170-2174. https://doi.org/10.1016/j.cub.2005.10.067

Darwin, C. (1868). The variation of animals and plants under domestication. (John Murray, Ed.). London.

De Marchi, M., Cassandro, M., Targhetta, C., Baruchello, M., \& Notter, D. R. (2005). Conservation of poultry genetic resource in the Veneto region of Italy. Animal Genetic Resources Information, (37). https:/ / doi.org/10.1017/CBO9781107415324.004 
genetic variability in two ancient chicken breeds of Padova area. Italian Journal of Animal Science, 4(Suppl. 3), 151-153. https://doi.org/10.4081/ijas.2005.3s.151

Di Giorgio, E., Loveland, J. L., Mayer, U., Rosa-Salva, O., Versace, E., \& Vallortigara, G. (2017). Filial responses as predisposed and learned preferences: Early attachment in chicks and babies. Behavioural Brain Research, 325, 90-104. https://doi.org/10.1016/j.bbr.2016.09.018

Egorova, O. V, \& Anokhin, K. V. (2003). Experimental analysis of the processes of systems genesis: expression of the c-fos gene in the chick brain during treatments inducing the development of the species-specific results-of-action acceptor. Neuroscience and Behavioral Physiology, 33(3), 209-216.

Formanek, L., Houdelier, C., Lumineau, S., Bertin, A., Cabanès, G., \& Richard-Yris, M.A. (2008). Selection of social traits in juvenile Japanese quail affects adults' behaviour. Applied Animal Behaviour Science, 112(1-2), 174-186. https://doi.org/10.1016/j.applanim.2007.07.004

Frahm, H. D., \& Rehkamper, G. (1998). Allometric comparison of the brain and brain structures in the White Crested Polish Chicken with UNcrsted Domestic Chicken Breeds. Brain Behav Evol, 52, 292-307.

Horn, G. (1985). Memory, imprinting, and the brain an inquiry into mechanisms. Oxford: Clarendon Press.

Horn, G. (2004). Pathways of the past: the imprint of memory. Nature Reviews. Neuroscience, 5(2), 108-120. https://doi.org/10.1038/nrn1324 
436 Johnson, M H, \& Horn, G. (1987). The role of a restricted region of the chick forebrain

437 in the recognition of individual conspecifics, 23, 269-275.

438 Johnson, Mark H., \& Horn, G. (1988). Development of filial preferences in dark-reared $439 \quad$ chicks. Animal Behaviour, 36, 675-683.

440 Jones, B. R., \& Merry, B. J. (1988). Individual or paired exposure of domestic chicks to

441 an open field: Some behavioural and adrenocortical consequences. Behavioural

442 Processes, 16, 75-86.

443 Jones, B. R., \& Williams, J. B. (1992). Responses of pair-housed male and female

444 domestic chicks to the removal of a companion. Applied Animal Behaviour Science, 32,

$445 \quad 375-380$.

446 Jones, R. B., Mills, A. D., \& Faure, J. M. (1996). Social discrimination in Japanese quail

447 Coturnix japonica chicks genetically selected for low or high social reinstatement

448 motivation. Behavioural Processes, 36(2), 117-124. https://doi.org/10.1016/0376-

$449 \quad 6357(95) 00024-0$

450 Kovach, J. (1990). Nonspecific Imprintability of Quail to Colors: Response to Artificial

451 Selection. Behavior Genetics, 20(1), 91-96.

452 Martinho III, A., \& Kacelnik, A. (2016). Ducklings imprint on the relational concept of

453 “same or different." Science, 353(6296), 286-288.

$454 \quad$ https://doi.org/10.1126/science.aaf4247

455 Mayer, U., Rosa-Salva, O., Lorenzi, E., \& Vallortigara, G. (2016). Social predisposition

456 dependent neuronal activity in the intermediate medial mesopallium of domestic 
457

458

459

460

461

462

463

464

465

466

467

468

469

470

471

472

473

474

475

476

477

chicks (Gallus gallus domesticus). Behavioural Brain Research, 310, 93-102.

https://doi.org/10.1016/j.bbr.2016.05.019

McCabe, B. J. (2013). Imprinting. Wiley Interdisciplinary Reviews: Cognitive Science, 4(4), 375390. https://doi.org/10.1002/wcs.1231

McCabe, B. J. (2019). Visual Imprinting in Birds: Behavior, Models, and Neural Mechanisms. Frontiers in Physiology, 10(May). https://doi.org/10.3389/fphys.2019.00658

Miao, Y.-W., Peng, M.-S., Wu, G.-S., Ouyang, Y.-N., Yang, Z.-Y., Yu, N., .. Zhang, Y.-P. (2013). Chicken domestication: an updated perspective based on mitochondrial genomes. Heredity, 110(3), 277-282. https://doi.org/10.1038/hdy.2012.83

Mills, A. D., \& Faure, J.-M. (1991). Divergent Selection for Duration of Tonic Immobility and Social Reinstatement Behavior in Japanese Quail (Coturnix coturnix japonica) Chicks. Journal of Comparative Psychology, 105(1), 25-38.

Mills, D., Jones, R. B., \& Michel, J. (1995). Species specificity of social reinstatement in Japanese quail of social reinstatement behaviour. Behavioural Processes, 34, 13-22.

Nicol, C. J. (2015). The Behavioural Biology of Chickens. Oxfordshire OX10 8DE (UK): CABI.

Rajecki, D. W., Ivins, B., \& Rein, B. (1976). Social discrimination and aggressive pecking in domestic chicks. Journal of Comparative and Physiological Psychology, 90(5), 442-452. https://doi.org/10.1037/h0077212

Rosa-Salva, O., Fiser, J., Versace, E., Dolci, C., Chehaimi, S., Santolin, C., \& Vallortigara, 
478

479

480

481

482

483

484

485

G. (2018). Spontaneous Learning of Visual Structures in Domestic Chicks. Animals, 8(8), 135. https://doi.org/10.3390/ani8080135

Schweitzer, C., Poindron, P., \& Arnould, C. (2009). Social Motivation Affects the Display of Individual Discrimination in Young and Adult Japanese Quail (Coturnix japonica). Developmental Psychobiology. https://doi.org/10.1002/dev.20370

Suarez, S. D., \& Gallup, G. G. (1983). Social reinstatement and open-field testing in chickens. Animal Learning \& Behavior, 11(1), 119-126.

Tibbetts, E. A. (2002). Visual signals of individual identity in the wasp Polistes fuscatus. Proceedings of the Royal Society B: Biological Sciences, 269(1499), 1423-1428. https://doi.org/10.1098/rspb.2002.2031

Tibbetts, E. A., \& Dale, J. (2007). Individual recognition: it is good to be different. Trends in Ecology and Evolution, 22(10), 529-537. https://doi.org/10.1016/j.tree.2007.09.001

Town, S. M. (2011). Preliminary evidence of a neurophysiological basis for individual discrimination in filial imprinting. Behavioural Brain Research, 225(2), 651-654. https://doi.org/10.1016/j.bbr.2011.08.018

Väisänen, J., \& Jensen, P. (2004). Responses of Young Red Jungle Fowl (Gallus gallus) and White Leghorn Layers to Familiar and Unfamiliar Social Stimuli. Poultry Science, 83(Poult Sci. 2004 Mar;83(3):335-43.), 335-343.

Vallortigara, G. (1992a). Affiliation and aggression as related to gender in domestic chicks (Gallus gallus). Journal of Comparative Psychology, 106(1), 53-57. https://doi.org/10.1037/0735-7036.106.1.53 
499 Vallortigara, G. (1992b). Affiliation and aggression as related to gender in domestic

500 chicks (Gallus gallus). Journal of Comparative Psychology (Washington, D.C. $\square$ : 1983), $106(1), 53-57$.

502

503

504

505

506

507

508

509

510

511

512

513

514

515

516

517

518

519

Vallortigara, G., \& Andrew, R. J. (1991). Lateralization of response by chicks to change in a model partner. Animal Behaviour, 41(2), 187-194.

https://doi.org/10.1016/S0003-3472(05)80470-1

Vallortigara, G., Cailotto, M., \& Zanforlin, M. (1990). Sex differences in social reinstatement motivation of the domestic chick (Gallus gallus) revealed by runway tests with social and nonsocial reinforcement. Journal of Comparative Psychology, 104(4), 361-367.

Vallortigara, G., Cozzutti, C., Tommasi, L., \& Rogers, L. J. (2001). How birds use their eyes: Opposite left-right specialization for the lateral and frontal visual hemifield in the domestic chick. Current Biology, 11(1), 29-33.

Vallortigara, G. (1992). Affiliation and Aggression As Related to Gender in Domestic Chicks (Gallus gallus). Journal of Comparative Psychology, 106(1), 53-57.

Vallortigara, G., \& Andrew, R. J. (1994). Differential involvement of right and left hemisphere in individua recognition in the domestic chick. Behavioural Processes, 33, $41-58$.

Vallortigara, G., \& Versace, E. (2018). Filial Imprinting. In Encyclopedia of Animal Behavior (pp. 1943-1948).

Verdiglione, R., \& Rizzi, C. (2018). A morphometrical study on the skull of Padovana 
520

521

522

523

524

525

526

527

528

529

530

531

532

533

534

535

536

537

538

539

540

chicken. Italian Journal of Animal Science, 0(0), 785-796.

https://doi.org/10.1080/1828051X.2017.1412810

Versace, E., Damini, S., Caffini, M., \& Stancher, G. (2018). Born to be asocial: newly hatched tortoises avoid unfamiliar individuals. Animal Behaviour, 138. https://doi.org/10.1016/j.anbehav.2018.02.012

Versace, E., Fracasso, I., Baldan, G., Dalle Zotte, A., \& Vallortigara, G. (2017). Newborn chicks show inherited variability in early social predispositions for hen-like stimuli. Scientific Reports, 7. https://doi.org/10.1038/srep40296

Versace, E., Schill, J., Nencini, A. M., \& Vallortigara, G. (2016). Nä̈ve chicks prefer hollow objects. PLoS ONE, 11(11). https://doi.org/10.1371/journal.pone.0166425

Versace, E., \& Vallortigara, G. (2015). Origins of knowledge: Insights from precocial species. Frontiers in Behavioral Neuroscience, 9(DEC). https://doi.org/10.3389/fnbeh.2015.00338

Versace, E. (2017). Precocial. In J. Vonk \& T. Shackelford (Eds.), Encyclopedia of Animal Cognition and Behavior (pp. 1-3). Cham: Springer International Publishing. https://doi.org/10.1007/978-3-319-47829-6_459-1

Versace, E., Caffini, M., Werkhoven, Z., \& Bivort, B. L. de. (2019). Individual, but not population asymmetries, are modulated by social environment and genotype in Drosophila melanogaster. BioRxiv, 694901. https://doi.org/10.1101/694901

Versace, E., Damini, S., Caffini, M., \& Stancher, G. (2018). Born to be asocial: newlyhatched tortoises spontaneously avoid unfamiliar individuals. Animal Behaviour, 138. 
https://doi.org/10.1101/152314

542 Versace, E., Fracasso, I., Baldan, G., Dalle Zotte, A., \& Vallortigara, G. (2017a).

$543 \quad$ Newborn chicks show inherited variability in early social predispositions for hen-like stimuli. Scientific Reports, 7(January), 40296. https:/ / doi.org/DOI:

Versace, E., Fracasso, I., Baldan, G., Dalle Zotte, A., \& Vallortigara, G. (2017b). stimuli. Scientific Reports, 7, 40296.

549

Versace, E., Martinho-Truswell, A., Kacelnik, A., \& Vallortigara, G. (2018). Priors in Animal and Artificial Intelligence: Where Does Learning Begin? Trends in Cognitive Sciences, 22(11), 963-925. https://doi.org/10.1016/j.tics.2018.07.005

Versace, E., Regolin, L., \& Vallortigara, G. (2006). Emergence of Grammar as Revealed by Visual Imprinting in Newly-hatched Chicks. In: The Evolution of Language. In Proceedings of the 6th International Conference, Rome, 12-15 April 2006.

Versace, E., Spierings, M. J., Caffini, M., ten Cate, C., \& Vallortigara, G. (2017). Spontaneous generalization of abstract multimodal patterns in young domestic chicks. Animal Cognition, 20(3), 521-529. https://doi.org/DOI 10.1007/s10071-017$1079-5$

Wood, S. M. W., \& Wood, J. N. (2015). A chicken model for studying the emergence of invariant object recognition. Frontiers in Neural Circuits, 9(February), 1-12. https://doi.org/10.3389/fncir.2015.00007 
562 Yurkovic, A., Wang, O., Basu, A. C., \& Kravitz, E. A. (2006). Learning and memory

563 associated with aggression in Drosophila melanogaster. Proceedings of the National

564 Academy of Sciences of the United States of America, 103(46), 17519-17524.

565 https://doi.org/10.1073/pnas.0608211103

566 Zajonc, R. B., Wilson, W. R., \& Rajecki, D. W. (1975). Affiliation and social

567 discrimination produced by brief exposure in day-old domestic chicks. Animal

568 Behaviour, 23(PART 1), 131-138. https://doi.org/10.1016/0003-3472(75)90059-7

569 Zanetti, E., De Marchi, M., Abbadi, M., \& Cassandro, M. (2011). Variation of genetic

570 diversity over time in local Italian chicken breeds undergoing in situ conservation.

571 Poultry Science, 90(10), 2195-2201. https://doi.org/10.3382/ps.2011-01527

572 Zanetti, E., De Marchi, M., Dalvit, C., \& Cassandro, M. (2010). Genetic characterization

573 of local Italian breeds of chickens undergoing in situ conservation. Poultry Science,

$574 \quad$ 89(3), 420-427. https://doi.org/10.3382/ps.2009-00324 